\title{
The mutations of project-based learning in the context of information services
}

\author{
Nicolas Szilas \\ Université de Genève, TECFA - FPSE, 42 bd Pont-d'Arve, CH-1211 Genève 4, Suisse
}

\begin{abstract}
From a use case concerning a master level course on pedagogical video games, this article describes how Project-Based Learning uses Internet-based services. Initially, Information services have been mostly used to facilitate communication between the students and the teacher, and to provide support in the project management. More recently, Internet has more deeply changed the philosophy of PBL, towards an increased integration into the real world. An innovative approach has emerged, in which products delivered by the students are both disseminated and reused for the course itself, for future classes.
\end{abstract}

\section{Project-Based Learning}

Project-Based Learning (PBL) is a constructivist teaching method that involves students into a project. More precisely, in the scope of this article, we will define PBL as a pedagogical approach where the main goal of the students is to build a product during the course $[1,2]$. In the process of achieving this goal, students learn new skills in the domain of the course. PBL has many pedagogical advantages, such as authenticity, development of autonomy, development of skills related to project management (group communication, planning, etc.), and increased motivation. PBL is not new, it has been widely used in engineering for example in the last quarter of the twentieth century. Interestingly however, in higher education in general, PBL is still considered as an innovative approach, certainly due to the fact that the culture of knowledge transmission is dominant in universities, compared to the culture of product making.

In the pre-internet era, PBL was happening in class (project's definition with the teacher, group work, teacher's guidance) and outside the class between students. An important component of PBL was information search, including technical documentation search, market/competitor analysis, and content search. How PBL evolved from this traditional approach - that was already using ICT in some extent, via database search — to the current digital era, characterized by the heavy use of the World Wide Web ? What are the benefits of using the WWW services for PBL ? How information technology could fundamentally change the PBL approach, beyond the mere providing of "useful tools" ? In this paper, we want to answer those questions through a specific case, a master course on educational video games given during the last 15 years through PBL.

This course, the VIP course (stemming from "Jeux VIdéo Pédagogique" in French), has been inherently based on ICT because it is part of a blended master, combining presence and distance periods. It is a 12 ECTS course, spanning a whole year, in which students work in groups to design and implement an educational video game (or serious game). Each game project is proposed to answer a demand formulated by a sponsor outside of the teaching unit of the master. Note that the product itself, the game, is a digital product, but not necessarily an online game. Also, in some cases, the game includes tangible elements and non-traditional interfaces. Beside this central design activity, several other activities are included, at the 
beginning of the course in particular. It includes analysing an existing serious game, reading a research article and writing a synthesis for this article, practicing on authoring tools.

Along the last 15 years, the course has been following the various transformations of the digital world, and has evolved accordingly. The article's structure will follow this evolution, starting from a technical use of ICT to a more innovative approach using Internet as a sharing space.

\section{Scaffolding services}

The blended nature of the course led us to use a web platform (Learning Management System — LMS) to support student-student and student-teacher communication. Such platforms not only enable students to work together even at distance but also provide a number of services to support students' activity, gathered in one single place: collaborative writing tools (such as wikis), information sharing (e.g. links), communication tools such as forums, etc. [3]. For example, in traditional PBL, regular fixed point meetings between students and the teacher were organized, to guide students and help them solving critical issues [1]. A web platform greatly improves the approach, because students can ask questions anytime on the forum and the teacher (or the tutor) can answer those questions quickly, all conversation's trace being kept at the same place. In the first years of this course, we used Moodle for that purpose.

While the centralized nature of LMS have clear advantages, it was not fully in line with the fundamental vision of PBL, involving a strong autonomy of students. How can students express themselves autonomously if they are constrained by a LMS such as Moodle, designed for any online teaching approach? One of the very promising approach regarding autonomy was the idea of Personal Learning Environments, derived from the Web 2.0 philosophy: students are encouraged to produce content on the web, not only consume it. In the context of PBL, producing content is not reduced to producing the final product, but also all kind of intermediary products: links, assets, ideas, plans, etc. All this is possible in an LMS such as Moodle but other tools allow a better appropriation of the content by the students, in the context of PBL [4]. We used as a replacement of Moodle Pageflakes, a now discontinued content aggregator that allowed users to gather and share links and personal services in a flexible and usable personal portal. Pageflakes was not dedicated to education and several features were missing such as centralized information, inter-group communication, etc. It had to be completed by a series of other tools: an online forum for global communication, a web page as a hub, a wiki and a collaborative writing services (Google Doc). Note also that moving from Moodle to Pageflakes and additional services is also a political change: the course is not stored by the institution anymore, which raises copyright issues and is not going without risks of discontinuity in service. Although a bit difficult to settle, this configuration was working. Nevertheless, we had expected that students would use more intensely the personalization capabilities of their PLE.

This last remark, and more prominently the explosion of social media in society, led us to reconsider the role of platforms in PBL. Progressively, students tended to less use the provided communication tools, in favour of their own tools. The major drawback of this behaviour is that teachers and tutors have no longer access to the communication and therefore cannot guide as efficiently as before. But it appeared not possible to change this trend, whatever the tools the teacher tried to provide. Therefore, the last version of the technopedagogical device finally contains less discussion and sharing services and focus on the three main types of services: communication (a social network), production (public wiki, Google Doc) and centralization (a static web page). 


\section{Opening to the world}

In this history of the VIP course's platforms, mirroring (part of) the history of the web, information services are used as facilitators of the PBL approach. However, the web is more than that. It has also become, to put it shortly, the new place where people live. Therefore, there is a unique opportunity for the products built during a PBL course to be disseminated through the Internet. When looking at the traditional practice and theory in PBL learning, despite a focus on the authenticity of the approach, the products are often only a "pretext" for knowledge acquisition, the product itself being often just discarded. To improve authenticity, motivation, and also utility, the VIP course attempts to valorise the PBL's products by publishing them on a lab's web site that gathers all games produced by the research lab [5]. Only games with sufficient quality are disseminated on this site, the moderation being performed by the teacher. In addition to the PBL's product, there are also other student's productions that are disseminated. The analysis of pedagogical video games are written in a wiki, the Edutech Wiki, a wiki on Educational technology [6]. Abstracts of theoretical papers, one of the course's activity, initially kept within the VIP course are now disseminated as a published Google Document, creating a collective annotated bibliography [7]. These last two productions are also moderated, respectively via an indicative warning for the analyses, and by a strict selection in the bibliography. Effectively, we consider that moderation is important in that case, so that potential users find the information relevant and reliable. In the long run, we would like most of productions in the VIP course to be disseminated.

Opening to the world also concerns the intrants of the project. First, the fact that projects come from an external sponsor immediately drives students into the real world. Second, students are encouraged to retrieve on the Internet assets, pieces of code, programming tips on various open resources, including resources created by our teaching/research unit. The course provides them pointers to such resources but students are also encouraged to search on their own.

\section{Closing the loop: the circular economy of PBL}

According to the metaphor of the "global village", the WWW is seen as place where contributors upload information which can be easily retrieved later by consumers. According to that conception, dissemination is equivalent to reuse. However, the WWW is rather an ocean of information, and there is limited chance that an information that is uploaded is finally used by someone. Therefore, rather than simply disseminating some information to the whole world, hoping it will be found by someone (as a message in a bottle), we developed the idea of a local economy of knowledge. The local sphere is the VIP course community, comprising students, teachers and assistants (tutors), as well as past and future students, past and future assistants and finally colleagues interested in the field. The key concept is that within this local community, contributions of students can be used as intrants, resources for other students. Produced knowledge is not anymore thrown away, nor disseminated for an uncertain use. It is reused by student [8]. For example, the annotated bibliography is a student contribution but also a resource that can be used by students to improve their knowledge. Games produced in the project may be analysed by students the next year. Bank of assets found by students are documented (in a wiki page) and used by following classes. We have progressively increased the number of such loops. Figure 1 represents the circular economy of products and resources for the VIP course. 


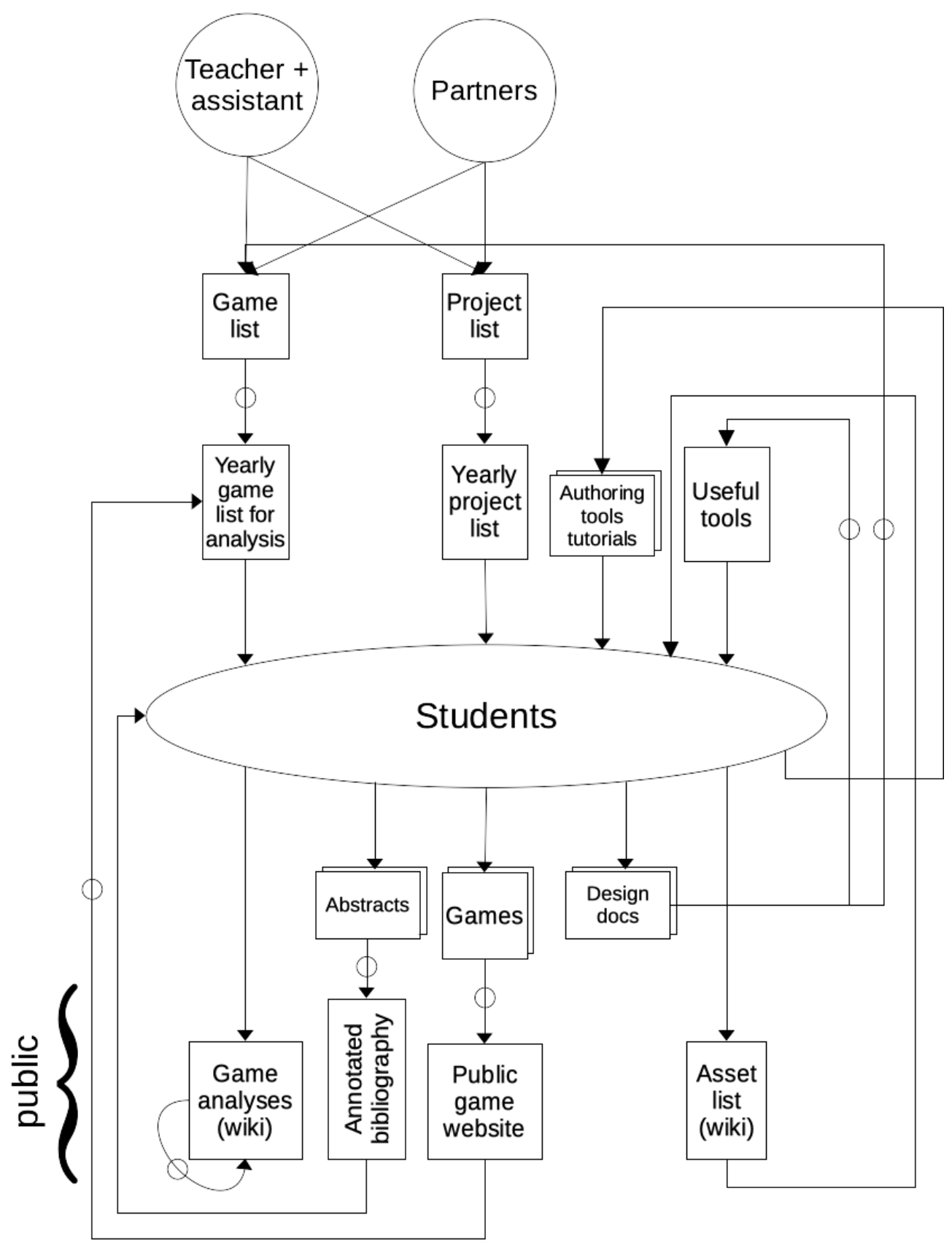

Fig. 1. Diagram illustrating the flow of student's resources and productions. The central part represents the main design process of production (the project), while other deliverables are also included. Moderation is represented by a circle in the arrow.

Figure 1 shows four public outputs of the course:

- A wiki section containing games analysed by students [6]. They are all published, but with the mention "In progress, draft" at the beginning of the page. These pages are regularly reviewed and if they are acceptable, the mention is withdrawn. This section now contains 122 analysed games. 
- An annotated bibliography, that started recently. Best evaluated abstracts produced by students are selected and placed in this public page (Google Doc). It now contains 6 abstracts. This bibliography serves as a theoretical resource for students, in the same class or in future classes.

- The public game website [5] that gathers games developed in our lab, both by students and researchers. The games disseminated in this website, are sometimes added by the teacher into the list of games to be analysed by students of a following year.

- An asset list that consists of a wiki page on copyright-free media [9]. This page both explains the principle of open licences for media and displays a comprehensive list of media banks. This list is a precious resource for students, when developing their games.

These four outputs are both disseminated freely on the Internet but also reused by the students, as part of the pedagogical scenario. Other outputs, not published are also reused: some of the various serious games students have identified in their background search are selected for future analysis by students, some tools identified by students are proposed to students in the upcoming classes and students are also asked to improve documentation and tutorials for the authoring tools they are using to make their games.

Regarding actors, we observed that some previous students, some previous assistants, some colleagues proposed games to be analysed or contacts for potential future projects. We have gathered these people into the "partners" category. This category is naturally growing and it constitutes a unique wealth for the course.

Information systems used to support this dynamics are a combination of various services, both hosted by the university and outside. It comprises:

A website developed with a content management system (CMS), Wordpress. The use of a CMS is an efficient way to promote the central production of the students, the games. The scope of this website is larger than the course itself as it covers all games developed in our laboratory. Therefore, it helps the promotion of the games.

- The Edutech Wiki: this is a large wiki developed in our research lab since 2006, that now gathers thousands of pages related to Educational Technology. The wiki philosophy (quick and easy editing) appears in line with PBL, because the main target being the final product (the game), students cannot spend much effort in other "side activities". Google Doc is used mostly as internal documentation, as it favours collaborative writing in a safe and reactive manner. It is also used for the annotated bibliography as a very simple way to publish the information, via the command "Publish to the web" in Google Doc. Alternatives were investigated but revealed too complex to settle.

\section{Towards autonomous yet scaffolded education}

PBL is a pedagogical approach that promotes students' autonomy. In practice, such autonomy requires from teachers and tutors both a strong effort in preparation and a closed guidance. We have seen in the previous section that the loop from productions to resources enables a continuous improvement of the course. This enables to envision that, if this process is further systematized and automated, it may be possible to make this course almost fully autonomous: project regularly fed by partners, game to analyse automatically extracted from student's activity and collected from teacher, assistants and partners, resources automatically updated via a systematic inclusion of resource sharing activities within the pedagogical scenario, all these processes being only slightly moderated by the teacher. Regarding evaluation, peer-to-peer evaluation, as well as involvement of the partners may be a relevant 
solution. Games could also be evaluated by the game's client, which has not been the case so far.

Such autonomous course may appear unfeasible, given the difficulties of Massively Open Online Courses (MOOCs) in terms of business model. But the PBL approach is radically different from current MOOCs, heavily based on video material production. In PBL, there is limited pedagogical content per se, because the value lies in the student's activity. Because this activity produces value (a useful game in the case of the VIP course), it could be effectively inserted within an economic system in which partners are ready to invest a little and contribute, in exchange of student's productions.

\section{Conclusion}

In this article, we have attempted to describe the relations between Project-Based Learning and Internet, through the use case of a specific master course, dedicated to educational game design. The first observation is that PBL seems to be heavily transformed in the Internet world:

- Facilitation of literature and background search.

- Increased communication between students and both the teaching staff and the project's sponsor.

- Possibility to manage the project-related information into a central virtual space.

- Dissemination of the project's outcomes to the world.

- Reuse of student's productions as resources for next year classes.

- Increased involvement of external partners in the management of the course.

These changes in PBL that we both observed and provoked seem to improve the quality of the project's outputs (more games per year are considered as publishable), the learner experience (example of student's comment: "I had the real feeling of being part of a learning community"), and hopefully the learning outcomes, although we did not measure all these factors. In the future we want to better assess engagement and learning in the course, and in which extent it is related to the proposed approach.

Beyond facilitating PBL, Internet is progressively moving PBL outside of the closed environment of the class, blurring the line between the class, where one learns new knowledge, and the society when one uses knowledge. Students are learners in the class and contributors outside of the class, and partners value their contribution.

It is noticeable however that PBL and its evolution do not necessarily fit with the current trends in e-learning, such as microlearning, gamification, or the use of statistical AI. PBL remains nowadays an approach for small scale courses and has not yet addressed the need for a massification of learning. Nevertheless, we believe that involving learners in projects can be implemented at a larger scale and that some of the mechanisms identified in this article could be useful and further automated to fit with larger classes.

Finally, our observations are based on a single course and whether they are valuable in other contexts remains an open question. A larger survey is the next step of this study, in order to better characterize PBL in higher education, and in which extent it has been influenced or transformed by the Internet. 


\section{References}

1. Mergendoller, J.R., Thomas, J.W.: Managing project based learning: Principles from the field. Annu. Meet. Am. Educ. Res. Assoc. (2000).

2. Thomas, J.W.: A review of research on project-based learning. The Autodesk Foundation, San Rafael, California (2000).

3. Synteta, P.: Project-Based e-Learning in higher education: The model and the method, the practice and the portal. Stud. Commun. New Media Educ. 263-269 (2003).

4. Benetos, K., Peraya, D.: Concevoir un dispositif hybride de formation pour favoriser l'apprentissage par projet. Les innovations pédagogiques en enseignement supérieur: pédagogies actives en présentiel et à distance. QPES Conference. pp. 711-719 (2013).

5. Jeux vidéo pédagogiques, http://tecfa.unige.ch/jeux.

6. Jeux pédagogiques, https://edutechwiki.unige.ch/fr/Catégorie:Jeux_pédagogiques.

7. Bibliographie annotée sur les jeux vidéo pédagogiques, https://tiny.cc/bibliographieJVP.

8. Schneider, D., Szilas, N., Da Costa, J., Class, B., Wang Szilas, J.: Towards a circular economy of learning environments. In: Theo Bastiaens, J. (ed.) EdMedia. pp. 1508-1518. Association for the Advancement of Computing in Education (AACE), Amsterdam, Netherlands (2019).

9. Médias libres d'utilisation, https://edutechwiki.unige.ch/fr/Médias_libres_d\%27utilisation. 